Original Article

Joumal of Epilepsy Research pISSN 2233-6249 / eISSN 2233-6257

Received April 19, 2019

Revised May 29, 2019

Accepted June 21, 2019

Corresponding author:

Hussein Algahtani, MD

King Abdulaziz Medical City, King Saud

bin Abdulaziz University for Health

Sciences, P.O. Box: 12723, Jeddah, 21483,

Saudi Arabia

Tel. +966-556633130

E-mail; halgahtani@hotmail.com

\title{
Perception and Attitude of the General Population towards Epilepsy in Jeddah, Saudi Arabia
}

\author{
Hussein Algahtani, MD¹, Bader Shirah, MD², Alhussain Alzahrani, MD³ , Mostafa Shaheen, MD \\ ${ }^{1}$ King Abdulaziz Medical City, King Saud bin Abdulaziz University for Health Sciences, Jeddah; ${ }^{2}$ King Abdullah \\ International Medical Research Center, King Saud bin Abdulaziz University for Health Sciences, Jeddah; ${ }^{3}$ King Saud \\ bin Abdulaziz University for Health Sciences, Jeddah, Saudi Arabia
}

Background and Purpose: There are several conflicting beliefs about epilepsy, and public awareness about this disease varies widely among different countries. The present study aimed to determine public perception and attitude regarding different aspects of epilepsy in Jeddah, Saudi Arabia. In addition, we aim to identify the cultural and religious beliefs in Saudi Arabia associated with the causes and treatment of epilepsy.

Methods: This is a cross-sectional study that was conducted between January 2018 and June 2018 in malls and public places in Jeddah, Saudi Arabia. This study utilized a self-administered questionnaire composed of 40 items.

Results: A total of 1,940 individuals participated in the study, of which 1,675 participants (86.3\%) had previously heard about epilepsy. Approximately $60 \%$ of the participants believed that epilepsy was caused by a brain disease and $17.1 \%$ believed that it is a genetic disease. Over $50 \%$ of the participants believed that epilepsy is treated with medications, $31.5 \%$ believed that it can be treated by the recitation of Quran, and $16.2 \%$ believed that it can be treated by surgery, while $10.2 \%$ believe that there is no treatment.

Conclusions: The results of the present study suggest that awareness about epilepsy in the general public should be raised to avoid a negative impact on the patients, their families, their communities, and the healthcare system. Several misconceptions were identified, particularly in the etiology and management of the disease. Increased awareness will help in the early diagnosis, appropriate care, and management of the patients, and lead to better social acceptance. Dissemination of information about epilepsy through social media should be considered to reach a great proportion of the general public.

(2019;9:42-50)

Key words: Perception, Attitude, Epilepsy, Saudi Arabia

\section{Introduction}

Epilepsy, or recurrent seizures, is a chronic and serious neurological disorder characterized by episodes of vigorous shaking and disturbed brain activities. ${ }^{1}$ There were only a small number of published studies about the condition in the Middle East, including Saudi Arabia, all of which were merely case reports and small community and hospital-based statistics. Prevalence of epilepsy in the Kingdom of Saudi Arabia is roughly estimated to be 6.54 per 1,000 people. ${ }^{2}$

Social acceptance of epilepsy patients is largely dependent on the perception of epilepsy in the community and it often represents a considerable problem for patients and their families. Helplessness, personal sensitivity, or the fear of being confronted with an episode of epileptic seizure was among the various reflections of members of the society towards patients with epilepsy. ${ }^{3}$ Some patients found social attitude towards their condition more devastating than the disorder itself. Information campaigns often successfully improve the knowledge and attitude of the general public toward epilepsy; however, detailed information about the target group is essential to organize a campaign successfully. ${ }^{4}$

There are several conflicting beliefs about epilepsy, and public awareness about this disease varies widely among different countries. ${ }^{5}$ 
Public awareness studies are important to successfully identify misunderstandings and misconceptions, which will help in designing targeted campaigns to improve the overall knowledge of the community. ${ }^{6}$ It is imperative to raise public awareness about epilepsy, to assist the patients and their families in seeking medical advice at the earliest. This leads to an early diagnosis of the disease, followed by immediate treatment for the patients and stress reduction for their caregivers. ${ }^{7}$ Negative perception of a disease significantly affects public interactions with both patients and caregivers. ${ }^{8}$

Although a number of studies have previously been conducted about the public perception and attitude towards epilepsy in Saudi Arabia, there were no detailed and extensive data that discuss different aspects of perception and beliefs associated with the disease in the country. ${ }^{9-16}$ The present study aimed to determine public perception and attitude towards different aspects of epilepsy in Jeddah, Saudi Arabia. Additionally, we aimed to identify the cultural and religious beliefs in Saudi Arabia about the etiology and treatment modalities of the disease. We also compared our results with previous studies conducted in Saudi Arabia with a significantly smaller number of participants, to assess the public opinion of such a common disorder.

\section{Methods}

This is a cross-sectional study that was conducted between January 2018 and June 2018 in malls and public places in Jeddah, Saudi Arabia. We utilized a stratified random sampling technique (probability sampling technique) to select the respondents. The inclusion criteria of this study were Arabic-speaking men and women from the general population who were above the age of 18 years. The exclusion criteria of this study were any man or woman younger than 18 years and epilepsy patients.

This study utilized a self-administered questionnaire composed of 40 items, which was developed in three phases namely: a preparatory phase, a pilot study phase, and a final revision phase. In the preparatory phase, we conducted a thorough literature review, and published studies concerning the perception and attitude towards epilepsy in the general population were reviewed. A questionnaire was then designed in simple and clear Arabic language to evaluate public perception and attitude toward epilepsy. The questionnaire was revised internally for a validity check, and a pilot study was conducted with 15 participants for a reliability check. Any issues identified in any of the questions were rectified, and the final modified ver- sion was validated and subsequently used in this study.

Thirty-four questions were included in the survey, categorized into three sources of information that included public knowledge about epilepsy, public attitudes toward epilepsy, and anticipated behavior toward epilepsy patients. Additionally, six questions were included to collect information about the demographic profile of the study participants.

All numerical values and demographic data obtained from the questionnaire were calculated and presented as frequency and percentage. We used descriptive statistics including mean, median, and standard deviation. All collected data were entered and analyzed through the IBM Statistical Package for the Social Sciences ver-

Table 1. Demographic profile of the participants

\begin{tabular}{|c|c|}
\hline Item & Value \\
\hline \multicolumn{2}{|l|}{ Gender } \\
\hline Male & $1,303(67.2)$ \\
\hline Female & $637(32.8)$ \\
\hline \multicolumn{2}{|l|}{ Age range (years) } \\
\hline $18-20$ & $464(23.9)$ \\
\hline $21-30$ & $656(33.8)$ \\
\hline $31-40$ & $446(23.0)$ \\
\hline $41-50$ & $231(11.9)$ \\
\hline $51-60$ & $58(3.0)$ \\
\hline More than 60 & $85(4.4)$ \\
\hline \multicolumn{2}{|l|}{ Education level } \\
\hline Uneducated & $117(6.0)$ \\
\hline Less than Bachelor & $888(45.8)$ \\
\hline Bachelor & $772(39.8)$ \\
\hline Masters & $114(5.9)$ \\
\hline $\mathrm{PhD}$ & $49(2.5)$ \\
\hline \multicolumn{2}{|l|}{ Nationality } \\
\hline Saudi & $1,405(72.4)$ \\
\hline Non-Saudi & $535(27.6)$ \\
\hline \multicolumn{2}{|l|}{ Monthly income } \\
\hline Less than 5,000 SR $(\$ 1,333)$ & $875(45.1)$ \\
\hline $5,000-10,000$ SR $(\$ 1,333-2,666)$ & $575(29.6)$ \\
\hline $10,000-15,000$ SR $(\$ 2,666-3,999)$ & $279(14.4)$ \\
\hline $15,000-20,000$ SR $(\$ 3,999-5,332)$ & $148(7.6)$ \\
\hline More than 20,000 SR $(\$ 5,332)$ & $63(3.3)$ \\
\hline \multicolumn{2}{|l|}{ Residential area } \\
\hline Jeddah city & $1,631(84.1)$ \\
\hline Other & 309 (15.9) \\
\hline
\end{tabular}

Values are presented as number (\%).

SR, Saudi Riyal. 
sion 23 (IBM Corp., Armonk, NY, USA).

All questionnaires were anonymous with no identifiers used. Confidentiality participant information was ensured. A cover page was included to explain confidentiality issues and instructions to complete the questionnaire. This study was approved by the Institutional Review Board of King Abdullah International Medical Research Center (KAIMRC).

\section{Results}

\section{Demographic profile}

A total of 1,940 individuals participated in the present study. Most of the participants were between the ages of 18 and 40 (80.7\%). The gender distribution showed that 1,303 participants were men (67.2\%) while 637 (32.8\%) were women. Majority of the participants were Saudi nationals $(72.4 \%$ ) and more than $80 \%$ of participants were inhabitants of Jeddah city, while the remaining were visitors. More than $70 \%$ of the participants had a monthly income of less than ten thousand Saudi Riyal $(\$ 2,666)$. Education level of majority of the participants was a bachelor's degree (39.8\%) and less than a bachelor's degree (45.8\%). The detailed demographic profile of the study participants is depicted in Table 1.

\section{Public knowledge about epilepsy}

Total 1,675 participants (86.3\%) had heard about epilepsy previously, and 1,422 (73.3\%) thought that epilepsy is not contagious. In addition, approximately $50 \%$ of the participants did not know if epilepsy affected sexual ability or pregnancy (Table 2).

More than $80 \%$ of the participants thought that epilepsy affected all ages. Approximately $60 \%$ of the participants believed that epilepsy is caused by a brain disease and $17.1 \%$ believed that it is a genetic condition. Around $21 \%$ of the participants considered epilepsy

Table 2. Public knowledge about epilepsy

\begin{tabular}{lccc}
\hline Question & Yes & No & Don't know \\
\hline $\begin{array}{l}\text { Did you ever hear about } \\
\text { epilepsy before? }\end{array}$ & $1,675(86.3)$ & $265(13.7)$ & 0 \\
$\begin{array}{l}\text { Do you think that } \\
\text { epilepsy is contagious? }\end{array}$ & $158(8.1)$ & $1,422(73.3)$ & $360(18.6)$ \\
$\begin{array}{l}\text { Does epilepsy affect the } \\
\text { sexual ability? }\end{array}$ & $427(22.0)$ & $537(27.7)$ & $976(50.3)$ \\
$\begin{array}{l}\text { Does epilepsy affect } \\
\text { pregnancy? }\end{array}$ & $475(24.5)$ & $484(24.9)$ & 981 (50.6) \\
\hline $\begin{array}{l}\text { Values are presented as number (\%). } \\
\text { (1) }\end{array}$ & &
\end{tabular}

Values are presented as number (\%).
Table 3. Public knowledge about epilepsy multiple choice questions

\begin{tabular}{|c|c|}
\hline Item & Value \\
\hline \multicolumn{2}{|l|}{ Do you know a certain age for epilepsy? } \\
\hline Affects all ages & $1,585(81.7)$ \\
\hline Children & $127(6.6)$ \\
\hline Young & $111(5.7)$ \\
\hline Elders & $96(5.0)$ \\
\hline I don't know & $21(1.1)$ \\
\hline \multicolumn{2}{|l|}{ What are the causes of epilepsy? } \\
\hline Punishment from God & $93(4.8)$ \\
\hline Evil eye or magic & $311(16.0)$ \\
\hline Brain disease & $1,190(61.3)$ \\
\hline Madness & $118(6.1)$ \\
\hline Mental retardation & $119(6.1)$ \\
\hline Genetic disease & $331(17.1)$ \\
\hline Psychological disease & $191(9.9)$ \\
\hline Without reason & $76(3.9)$ \\
\hline I don't know & $258(13.3)$ \\
\hline Other & $81(4.2)$ \\
\hline \multicolumn{2}{|c|}{$\begin{array}{l}\text { What are your main sources of information } \\
\text { about epilepsy? }\end{array}$} \\
\hline Personal experience & $293(15.1)$ \\
\hline Relatives and friends & $834(43.0)$ \\
\hline Television & $456(23.5)$ \\
\hline Internet & $685(35.3)$ \\
\hline School or university & $343(17.7)$ \\
\hline Books, magazines, and newspapers & $154(7.9)$ \\
\hline Physician & $92(4.7)$ \\
\hline Other & $82(4.2)$ \\
\hline \multicolumn{2}{|l|}{ What are the symptoms of epilepsy? } \\
\hline Strange movements & $603(31.1)$ \\
\hline Fainting & $663(34.2)$ \\
\hline Hallucination & $301(15.5)$ \\
\hline Headache & $301(15.5)$ \\
\hline Convulsions and muscle spasms & $1,154(59.5)$ \\
\hline I don't know & $168(8.7)$ \\
\hline \multicolumn{2}{|c|}{ Do you think epilepsy is more dangerous than? } \\
\hline Cancer & $90(4.6)$ \\
\hline Diabetes & $505(26.0)$ \\
\hline AIDS & $123(6.3)$ \\
\hline Stroke & $198(10.2)$ \\
\hline Neurological diseases & $564(29.5)$ \\
\hline It is not dangerous & $599(30.9)$ \\
\hline \multicolumn{2}{|l|}{ How to treat epilepsy patients? } \\
\hline There is no treatment & $197(10.2)$ \\
\hline With medications & $1,035(53.4)$ \\
\hline Surgery & $315(16.2)$ \\
\hline With the recitation of Quran & $611(31.5)$ \\
\hline Herbal therapy & $153(7.9)$ \\
\hline Traditional cauterization & $74(3.8)$ \\
\hline Electric shock & $83(4.3)$ \\
\hline With yoga and meditation & $85(4.4)$ \\
\hline I don't know & $334(17.2)$ \\
\hline
\end{tabular}

Values are presented as number (\%).

AIDS, acquired immune deficiency syndrome. 
as a punishment from God, evil eye, or magic. About $12 \%$ of the participants believed that epilepsy is a form of madness or mental retardation and $9.9 \%$ believed that it is a psychological disorder.

The main sources of information for the participants about epilepsy were relatives and friends (43.0\%), the internet (35.3\%), and the television (23.5\%). Around $20 \%$ of the participants knew about epilepsy from physicians, books, magazines, and newspapers. The most selected options regarding symptoms of epilepsy were muscle spasms (59.5\%), fainting (34.2\%), and strange movements (31.1\%).

Approximately $30 \%$ of the participants thought that epilepsy is not dangerous, while $29.5 \%$ thought it is more dangerous than other neurological diseases. A large percentage of the participants thought it is more dangerous than diabetes (26\%), stroke (10.2\%), acquired immune deficiency syndrome (AIDS) (6.3\%), and cancer (4.6\%). Over $50 \%$ of the participants believed that epilepsy is treated with medications, $31.5 \%$ believed that it can be treated by the recitation of Quran, and $16.2 \%$ believed that it can be treated by surgery, while $10.2 \%$ believed that there is no treatment (Table 3 ).

\section{Public attitudes towards epilepsy}

Total 1,178 participants (61.2\%) said that they did not have a family member or friend who had epilepsy and 1,143 (58.9\%) said that they would not lie about epilepsy to a family member. In addition, 1,257 (64.8\%) believed that an epilepsy patient can be an active member of the society and 1,279 (65.9\%) thought that an epilepsy patient should not be isolated from society. Around $36 \%$ of the participants believed that society treats epilepsy patients with stigmatization.
More than $50 \%$ of the participants considered it possible to go to a public place with an epilepsy patient and if they were managers, they would hire patients with epilepsy. Around $45 \%$ of the participants had not seen a seizure before and $47.6 \%$ did not know how to deal with a seizure if it were to occur in their presence. Approximately $50 \%$ of the participants would not allow their child to play with an

Table 5. Public attitudes towards epilepsy multiple choice questions

\begin{tabular}{lc}
\hline Item & Value \\
\hline What do you think you can do to help someone & \\
who is having a seizure? & $156(8.0)$ \\
Nothing & $382(19.7)$ \\
Tongue holding & $508(26.2)$ \\
Spray water in the face & $823(42.4)$ \\
Head protection & $684(35.3)$ \\
Stay near the person & $367(18.9)$ \\
Direct the body and head to a side & $99(5.1)$ \\
Shake the person & $687(35.4)$ \\
Fix the position of the person & $245(12.6)$ \\
Place strong odor near the nose & $214(11.0)$ \\
Other & \\
What do you feel when you see someone who is & \\
having a seizure in front of you? & $338(17.4)$ \\
Fear & $42(2.2)$ \\
Carelessness & $518(26.7)$ \\
Compassion & $187(9.6)$ \\
Desire to escape & $1,423(73.3)$ \\
Desire to help & $211(10.9)$ \\
Weakness &
\end{tabular}

Values are presented as number (\%).

Table 4. Public attitudes towards epilepsy

\begin{tabular}{lrrc}
\hline Question & Yes & No & Don't know \\
\hline Is there any family member or friend who is suffering from epilepsy? & $606(31.2)$ & $1,178(61.2)$ & $147(7.6)$ \\
Would you lie about epilepsy in a family member? & $455(23.5)$ & $1,143(58.9)$ & $342(17.6)$ \\
Do you think that epilepsy patient can be an active member of the society? & $1,257(64.8)$ & $336(17.3)$ & $347(17.9)$ \\
Do you think society treats epilepsy patients with stigmatization? & $707(36.4)$ & $770(39.7)$ & $463(23.9)$ \\
Do you think that epilepsy patient should be isolated from the society? & $388(20.0)$ & $1,279(65.9)$ & $273(14.1)$ \\
Is it possible to go to a public place with an epilepsy patient? & $1,144(59.0)$ & $436(22.4)$ & $360(18.6)$ \\
If you were a manager, would you hire a patient with epilepsy? & $999(51.5)$ & $443(22.8)$ & $498(25.7)$ \\
Have you seen a seizure before? & $851(43.9)$ & $856(44.1)$ & $233(12.0)$ \\
Would you marry or marry your son or daughter to a patient with epilepsy? & $473(24.4)$ & $938(48.3)$ & $529(27.3)$ \\
Would you be a friend with a patient with epilepsy? & $863(44.5)$ & $714(36.8)$ & $363(18.7)$ \\
If you have a child, would you allow him to play with an epilepsy patient? & $647(33.4)$ & $957(49.3)$ & $336(17.3)$ \\
Do you know how to deal with a seizure if it occurs in front of you? & $614(31.6)$ & $923(47.6)$ & $403(20.8)$ \\
\hline
\end{tabular}

Values are presented as number (\%). 
epilepsy patient and would not marry or allow their son or daughter to be married to an epilepsy patient. In addition, 36.8\% would not befriend an epilepsy patient while $44.5 \%$ said they would (Table 4).

Regarding what the participants thought they can do to help someone having a seizure, more than $40 \%$ said they would protect the head, $35.4 \%$ would fix the position of the person, and $35.3 \%$ would stay near the person. More than $70 \%$ of the participants said they would curb the desire to help someone having a seizure. Other common feelings included compassion (26.7\%) and fear (17.4\%) (Table 5).

\section{Anticipated behaviors towards epilepsy patients}

Total 828 participants (42.7\%) thought that the lifespan of epilepsy patients is like others. Approximately $60 \%$ of the participants believed that epilepsy patients could marry and have children. More than $40 \%$ of the participants thought that epilepsy patients could drive a car and $77.4 \%$ thought that epilepsy patients can play sports. More than $50 \%$ of the participants thought that the mental abilities of epilepsy patients were like others. Around $70 \%$ of the participants thought that epilepsy patients can continue education and more than $65 \%$ thought that epilepsy patients can get a job. More than $55 \%$ of the participants believed that epilepsy patients should not study in a separate school. More than $40 \%$ of the participants thought that epilepsy patients needed psychotherapy (Table 6).

\section{Discussion}

This study was conducted in Jeddah city; the main gateway to the cities of Makkah and Medina and the second largest city in Saudi
Arabia. Although several studies from Saudi Arabia to assess perception and attitude of the general population towards epilepsy have been published, ${ }^{9-16}$ this is the first comprehensive publication and the third largest in terms of the number of participants recruited. In addition, the results of this paper will indicate if there is a change in the perception and knowledge in the Saudi community and whether there is a difference between Jeddah city and other cities and regions in the Kingdom. In addition to recruiting a large number of respondents, we also compared our results with previously published studies from Saudi Arabia.

Our study targeted the general public in Jeddah city in Saudi Arabia with the majority of participants being less than the age of 40 . Most of the respondents were educated, reflecting on the contribution of the government towards education. The respondent's demographics were similar to the other published studies from the Kingdom of Saudi Arabia; therefore, this study can be considered as a representation of the general public.

In the past few years there has been a significant progress in the efforts to understand the several clinical and therapeutic aspects of epilepsy, along with its etiologies and risk factors, such as genetics. ${ }^{17}$ This was observed in our study, since majority of the participants had previously heard about epilepsy, which is consistent with the education levels of our study population and previously published studies (range, 77.4-95\%). ${ }^{10}$ Although our study is similar to other studies from Saudi Arabia, the percentage of respondents who did not hear about epilepsy was still considerably high (13.7\%) than the United States $^{18}(5 \%)$, New Zealand ${ }^{19}(5 \%)$, and Kuwait ${ }^{20}(2.4 \%)$.

Around $8 \%$ of the respondents in our study thought that epilepsy is contagious, which is consistent with previously published data

Table 6. Anticipated behaviors towards epilepsy patients

\begin{tabular}{lrrc}
\hline Question & \multicolumn{1}{c}{ Yes } & No & Don't know \\
\hline Do you think that the lifespan of the epilepsy patient is like others? & $828(42.7)$ & $499(25.7)$ & $613(31.6)$ \\
Do you think that epilepsy patient can marry? & $1,225(63.1)$ & $195(10.1)$ & $520(26.8)$ \\
Do you think that epilepsy patient can have children? & $1,108(57.1)$ & $205(10.6)$ & $627(32.3)$ \\
Do you think that epilepsy patient can drive a car? & $860(44.3)$ & $652(33.6)$ & $428(22.1)$ \\
Do you think that epilepsy patient can continue education? & $1,408(72.6)$ & $226(11.6)$ & $306(15.8)$ \\
Do you think that epilepsy patient should study in a separate school? & $470(24.2)$ & $1,117(57.6)$ & $353(18.2)$ \\
Do you think that epilepsy patient can get a job? & $1,283(66.1)$ & $250(12.9)$ & $407(21.0)$ \\
Do you think that epilepsy patients can play sports? & $1,501(77.4)$ & $173(8.9)$ & $266(13.7)$ \\
Do you think that the mental abilities of epilepsy patient are like others? & $1,121(57.8)$ & $406(20.9)$ & $413(21.3)$ \\
Do you think an epilepsy patient needs psychotherapy? & $847(43.7)$ & $615(31.7)$ & $478(24.6)$ \\
\hline
\end{tabular}

Values are presented as number (\%). 
(range, 3.5-21.2\%). ${ }^{10}$ This finding indicates a lack of awareness and understanding about the nature of the disease and its etiologies in the general population.

Although uncontrolled epilepsy may affect sexual abilities or outcomes of pregnancy, antiepileptic drugs and the psychological complications associated with the disease are the main causes that may affect the same. ${ }^{21,22}$ Effects of epilepsy on pregnancy and sexual abilities is an area that had not been previously explored. More than half of the participants in our study did not know whether epilepsy affects sexual abilities or pregnancy. This could reflect either culturally related barriers of knowledge or the lack of proper campaigns that address such sensitive issues.

Patient age, was another factor that was not previously explored in the studies conducted in Saudi Arabia. In our study, more than $80 \%$ of individuals believed that epilepsy affected all ages. This is true since epilepsy affects all age groups with a bimodal distribution (childhood and elderly). ${ }^{1}$

Regarding the causes of epilepsy, most of the participants thought that epilepsy is a brain disease or a genetic disorder. Surprisingly, punishment from God, evil eye, madness, psychological disease, and other misconceptions still exist. When comparing our results with other studies from Saudi Arabia, there was a remarkable improvement in the people's understanding of the causes of epilepsy with significantly less focus on false concepts such as punishment from God or evil eye. ${ }^{9-16}$ In a study conducted by Obeid et al. ${ }^{16}$ in 2012 among university-educated school teachers and undergraduate students, $45.3 \%$ of the respondents believed that epilepsy is caused by possession of Jinn (demons). This is also consistent with previous studies coming from Saudi Arabia. ${ }^{9-15}$

Pertaining to the manifestations of epilepsy, the highest proportion of respondents selected convulsions and muscle spasms, fainting, and strange movements. Although headache could be one of the manifestations of epilepsy, it is not considered pathognomonic. Compared to other studies from Saudi Arabia, our findings were different from previously published data. ${ }^{9-16}$ The number of respondents who did not know the answer, was definitely better than the previously published data from Alaqeel and Sabbagh ${ }^{10}$ (19.9\%).

Regarding epilepsy treatment, only $53.4 \%$ believed the medications can help in the treatment of epilepsy. Around one-third of the participants believed in faith and spiritual treatment with the recitation of Quran, the Islamic holy book. In 7.9\% of the respondents, herbal medicine was selected as a form of treatment for epilepsy. These results have been previously reported in several Arab countries such as Kuwait. ${ }^{20}$ Around $10 \%$ of the respondents believed that epilepsy was untreatable, which is a reflection of cultural beliefs in Saudi Arabia. This is in alignment with previous studies conducted in Riyadh, ${ }^{10,12}$ Asir, $^{13}$ United Arab Emirates, ${ }^{23}$ and Ethiopia. ${ }^{24}$ Only $16.2 \%$ of the respondents believed that surgery is a treatment option for epilepsy. Around $17 \%$ of the participants did not know whether there was a treatment for epilepsy. Public educational campaigns should be encouraged as this can improve the knowledge regarding different treatment modalities of epilepsy. Our results showed that the knowledge of the Saudi public regarding treatment of epilepsy did not demonstrate any improvements when compared to other studies conducted in different regions of Saudi Arabia. ${ }^{9-16}$

Around one-third of the participants believed that epilepsy is not dangerous and another one-third believed that epilepsy is more dangerous than other neurological disorders. Several respondents believed that epilepsy is not more dangerous than diabetes mellitus, stroke, AIDS, and cancer. Although this question was vague and differences between different neurological disorders was not clear, this is definitely an underestimation of the seriousness and outcomes of epilepsy.

Saudi Arabia has dramatically improved in the past few years with several changes observed in the community such as the widespread use of internet and social media and the decline in the use of paper-based knowledge sources such as books, magazines, and newspapers. ${ }^{25}$ This was reflected in our study since the major sources of information, for the participants, were the internet and television. Alternatively, healthcare has witnessed a significant improvement with more than 500 hospitals being established in Saudi Arabia. ${ }^{26}$ Despite this, less than $5 \%$ of our participants knew about epilepsy from physicians. This indicates that hospitals and physicians need to contribute more by educating the society about common diseases including epilepsy. Personal experience and word of mouth from relatives and friends significantly influences information regarding epilepsy in the Saudi community.

Beliefs and attitudes of the people towards health were significantly affected by culture. Cultural stigma and misconceptions about epilepsy may have catastrophic consequences including delay in diagnosis and disease management. ${ }^{27}$ This was reflected in our study, since approximately $24 \%$ of respondents would lie about a family member suffering from epilepsy and around $17 \%$ did not know whether they would do so or not. Additionally, more than one-third of the participants thought that the society treats epilepsy patients with stigmatization and that they should be isolated from 
society. The impact of stigmatization is significantly high due to the fact that this stigma is not only attached to the individual with epilepsy but also his/her family. ${ }^{28}$ Approximately $60 \%$ of the participants would consider going to a public place with an epilepsy patient, which indicated an openness from a large proportion of the society regarding epilepsy patients; however, this proportion needs to be increased.

Epilepsy can affect employment due to the nature of the disease, medications, financial costs related to insurance, paid sick leaves, and other factors related to social stigma. The stigma alone can make it more difficult for epilepsy patients to find jobs. Even if seizures were fully controlled by medications or surgery, many employers were reluctant to hire a patient with epilepsy. ${ }^{29}$ Around half of our respondents would hire a patient with epilepsy if they were managers and the other half would not, were hesitant, or did not know. This was a very high proportion in comparison with other countries such as $\operatorname{Turkey}^{30}(13.7 \%)$, Austria ${ }^{31}(9 \%)$, Italy ${ }^{32}(15 \%)$, the United Arab Emirates $^{23}(10 \%)$, and New Zealand ${ }^{19}(3 \%)$.

More than $75 \%$ of our respondents would not marry or allow their child to marry an epilepsy patient. This was consistent with findings of other studies in Greece ${ }^{33}(66 \%)$, Turkey ${ }^{30}(73.8 \%)$, and the United Arab Emirates ${ }^{23}(68 \%)$. These numbers were definitely much higher than developed countries such as Austria ${ }^{31}(15 \%)$ and New Zealand $^{19}(5 \%)$. The possible reason behind such a discrepancy could be that in most Asian countries, it is the responsibility of the parents to find a suitable match for their offspring and arrange their marriage. In addition, parents of patients with epilepsy would choose not to inform the spouse and his/ her family about their child's condition prior to the marriage. Therefore, due to the previously mentioned reasons, divorce ensued when epilepsy becomes evident. Honest and prospective communication during marriage negotiations is important to ensure a successful marriage. Other reasons include fear of passing the disease to the offspring and belief of not being able to fulfill social and economic obligations and roles. 34,35

More than half of the participants would not allow their child to play with or befriend an epilepsy patient. This is similar to the studies reported in Riyadh ${ }^{10}(73 \%)$ and Majmaah ${ }^{14}(49 \%)$. This finding reflects the degree of discrimination and misrepresentation of epilepsy in this society. Therefore, there is a great need for more social and cultural awareness to end this stigma.

Less than half of the participants reported that they had seen someone having a seizure. This result was similar to that of other studies performed in the United Arab Emirates ${ }^{23}(42.3 \%)$, Riyadh ${ }^{10}$
$(42.7 \%)$, and Austria ${ }^{31}$ (36\%). Surprisingly, more than half of the participants did not know how to deal with a seizure if it were to occur in their presence. In addition, a substantial percentage of the respondents would take incorrect measures to help someone having a seizure such as: holding their tongue, fixing their position, or placing a strong odor near the nose. Although more than $70 \%$ would feel a desire to help, some respondents would feel weakness, fear and anxiety, or have the desire to escape.

More than half of the respondents did not know or thought that the lifespan of the epilepsy patients differed from others. Despite this, more than half of the respondents believed that an epilepsy patient can marry and can have children. A previously speculated factor influencing the acceptance of the public to marry an epileptic patient was the concern that the disease may be inherited. In our study, around $17 \%$ of the respondents thought that epilepsy could be a hereditary disorder.

Inability to drive has repeatedly been considered as a major concern for epilepsy patients. ${ }^{36}$ More than half of the participants believed that an epilepsy patient could not drive a car. Additionally, a significant number thought that epilepsy patients cannot play sports and their mental abilities are like others.

Epilepsy patients experience a wide range of behavioral disturbances such as affective symptoms, depression, aggression, agitation, and psychosis. These disturbances are associated with frequent visits to psychiatry clinics, increased use of psychotropic medications, and increased caregiver burden. Given the nature of the psychiatric disturbances in epilepsy patients, psychotherapy, behavioral interventions, and environmental modifications may be among the most helpful strategies to manage such undesired behaviors in patients with epilepsy. ${ }^{37}$ Around half of the participants thought that epilepsy patients need psychotherapy.

In our questionnaire, we added a "don't know" response option to most of the questions, which helped us identify the knowledge gaps in the public perception towards epilepsy. A substantial percentage of the participants were not sure regarding several questions about epilepsy and epilepsy patients. Specifically, the lack of knowledge about available treatment modalities for epilepsy, which may delay them from seeking appropriate treatment to improve their quality of life.

Our study is one of a few studies that thoroughly investigated the amount of knowledge regarding epilepsy in the general public. It identified a number of gaps in knowledge about several aspects of epilepsy among the Saudi general population. There is a need to raise 
awareness regarding epilepsy in the Saudi general population. Despite some limitations of the present study, we believe that our results help advance the understanding, perception, and knowledge regarding epilepsy in Saudi Arabia.

Despite advancements in the field of epilepsy worldwide, perception and attitude of the general public towards several aspects of epilepsy in Saudi Arabia were still lagging behind. We identified several misconceptions regarding the information and attitude toward epilepsy in Saudi Arabia, particularly those related to the etiology and management of the disease. Results of the present study suggest that public awareness about epilepsy should be raised to avoid a negative impact on epilepsy patients, their families, their communities, and the healthcare system. The findings of this study indicate that providing more information about epilepsy, through public education and awareness campaigns, would be beneficial and valuable for the general population. There is a need to raise awareness about epilepsy in the general population of Saudi Arabia, to assist epilepsy patients in being accepted and de-stigmatized in the community by improving healthcare administration and quality of life. Dissemination of information about epilepsy through social media should be considered to reach a great proportion of the general public.

\section{Conflicts of Interest}

The authors declare that they have no conflicts of interest.

\section{References}

1. Karasin $\mathrm{B}$, Karasin M. Epilepsy: clinical review and surgical options. AORN J 2017; 106:393-414.

2. Shahid R, Nazish S, Zafar A, et al. Epidemiological study of epilepsy from a tertiary care hospital in kingdom of Saudi Arabia. Neurosciences (Riyadh) 2018;23:223-6.

3. Daoud A, Al-safi S, Otoom S, Wahba L, Alkofahi A. Public knowledge and attitudes towards epilepsy in Jordan. Seizure 2007;16:521-6.

4. Kartal A, Akyıldı A. Public awareness, knowledge, and practice relating to epilepsy among adults in Konya. Epilepsy Behav 2016;59:137-41.

5. Tiamkao S, Sawanyawisuth K, Singhpoo K, Ariyanuchitkul S, Ngamroop $\mathrm{R}$; Integrated Epilepsy Research Group. Differences of knowledge, attitudes, and behaviors towards epilepsy between populations in municipal and nonmunicipal areas. Psychol Res Behav Manag 2013;6:111-6.

6. Alsharif MM, El-fetoh NMA, Ali GY, et al. Epilepsy as a health problem among school children in Turaif, Northern Saudi Arabia, 2017. Electron Physician 2017;9:5036-42.

7. Alkhamees $H A$, Selai CE, Shorvon SD. The beliefs among patients with epilepsy in Saudi Arabia about the causes and treatment of epilepsy and other aspects. Epilepsy Behav 2015;53:135-9.

8. Abduelkarem AR. Societal problems that patients with epilepsy are facing in Sharjah, UAE. Epilepsy Behav 2016;59:142-6.

9. Al-Dossari KK, Al-Ghamdi S, Al-Zahrani J, et al. Public knowledge awareness and attitudes toward epilepsy in Al-Kharj Governorate Saudi Arabia. J Family Med Prim Care 2018;7:184-90.

10. Alaqeel A, Sabbagh AJ. Epilepsy; what do Saudi's living in Riyadh know? Seizure 2013;22:205-9.

11. Alaqeel A, Kamalmaz $\mathrm{H}$, Abou Al-Shaar $\mathrm{H}$, et al. Evaluating the initial impact of the Riyadh Epilepsy Awareness Campaign. Epilepsy Behav 2015;52(Pt A):251-5.

12. Muthaffar OY, Jan MM. Public awareness and attitudes toward epilepsy in Saudi Arabia is improving. Neurosciences (Riyadh) 2014;19:124-6.

13. Alhazzani AA, Alqahtani AM, Abouelyazid A, et al. Public awareness, knowledge, and attitudes toward epilepsy in the Aseer region, Saudi Arabia - a community-based cross-sectional study. Epilepsy Behav 2016; 63:63-6.

14. Almutairi AM, Ansari T, Sami W, Baz S. Public knowledge and attitudes toward epilepsy in Majmaah. J Neurosci Rural Pract 2016;7:499-503.

15. Altowayan $R$, Aloqaily $H$, Almutairi $A$, et al. Level of awareness and attitudes toward epilepsy in Qassim, Saudi Arabia: a cross-sectional study. Epilepsy Behav 2018;90:66-9.

16. Obeid T, Abulaban A, Al-Ghatani F, Al-Malki AR, Al-Ghamdi A. Possession by 'Jinn' as a cause of epilepsy (Saraa): a study from Saudi Arabia. Seizure 2012;21:245-9.

17. Helbig I. Genetic causes of generalized epilepsies. Semin Neuro/ 2015; 35:288-92.

18. Caveness WF, Merritt HH, Gallup GH Jr. A survey of public attitudes toward epilepsy in 1974 with an indication of trends over the past twenty-five years. Epilepsia 1974;15:523-36.

19. Hills MD, MacKenzie HC. New Zealand community attitudes toward people with epilepsy. Epilepsia 2002;43:1583-9.

20. Awad A, Sarkhoo F. Public knowledge and attitudes toward epilepsy in Kuwait. Epilepsia 2008;49:564-72.

21. Khuda I, Aljaafari D. Epilepsy in pregnancy. A comprehensive literature review and suggestions for saudi practitioners. Neurosciences (Riyadh) 2018;23:185-93.

22. Ernst LD. Let's talk about sex: integrating sex as a biological variable into epilepsy research. Epilepsy Curr 2018;18:292-4.

23. Bener A, al-Marzoogi FH, Sztriha L. Public awareness and attitudes towards epilepsy in the United Arab Emirates. Seizure 1998;7:219-22.

24. Deresse B, Shaweno D. General public knowledge, attitudes, and practices towards persons with epilepsy in South Ethiopia: a comparative community-based cross-sectional study. Epilepsy Behav 2016;58:106-10.

25. Meo SA, Hassan A, Usmani AM. Research progress and prospects of Saudi Arabia in global medical sciences. Eur Rev Med Pharmacol Sci 2013;17:3265-71.

26. Ministry of Health. Statistical Yearbook [Internet]. Riyadh: Ministry of Health, [cited 2018 Dec 24]. Available at: https://moh.gov.sa/en/ 
Ministry/Statistics/Book/Pages/default.aspx.

27. Thomas SV, Nair A. Confronting the stigma of epilepsy. Ann Indian Acad Neurol 2011;14:158-63.

28. de Boer HM. Epilepsy stigma: moving from a global problem to global solutions. Seizure 2010;19:630-6.

29. Fraser RT, Weber PB, Laxer KD, Post T. Considering developing a specialized epilepsy employment program? The PEP Jobs Program paradigm. Epilepsy Behav 2018;82:194-5.

30. Bekiroğlu N, Ozkan R, Gürses C, Arpaci B, Dervent A. A study on awareness and attitude of teachers on epilepsy in Istanbul. Seizure 2004;13: 517-22.

31. Spatt J, Bauer G, Baumgartner $C$, et al. Predictors for negative attitudes toward subjects with epilepsy: a representative survey in the general public in Austria. Epilepsia 2005;46:736-42.

32. Canger $\mathrm{R}$, Cornaggia C. Public attitudes toward epilepsy in Italy: results of a survey and comparison with U.S.A. and West German data. Epilepsia 1985;26:221-6.

33. Diamantopoulos N, Kaleyias J, Tzoufi M, Kotsalis C. A survey of public awareness, understanding, and attitudes toward epilepsy in Greece. Epilepsia 2006;47:2154-64.

34. Santosh D, Kumar TS, Sarma PS, Radhakrishnan K. Women with onset of epilepsy prior to marriage: disclose or conceal? Epilepsia 2007;48: 1007-10.

35. Tedrus GM, Fonseca LC, Pereira RB. Marital status of patients with epilepsy: factors and quality of life. Seizure 2015;27:66-70.

36. Drazkowski J. An overview of epilepsy and driving. Epilepsia 2007;48 Suppl 9:10-2.

37. Leeman-markowski BA, Schachter SC. Cognitive and behavioral interventions in epilepsy. Curr Neurol Neurosci Rep 2017;17:42. 